\title{
Elderly patients attended in emergency health services in Brazil: a study for victims of falls and traffic accidents
}

\author{
Mariana Gonçalves de Freitas ${ }^{1}$ \\ Palmira de Fátima Bonolo ${ }^{2}$ \\ Edgar Nunes de Moraes ${ }^{3}$ \\ Carla Jorge Machado ${ }^{4}$
}

${ }^{1}$ Departamento de Vigilância de Doenças e Agravos Não Transmissíveis e Promoção da Saúde, Secretaria de Vigilância em Saúde, Ministério da Saúde. SAF Sul, Trecho $2 /$ Lote $05 / 06$, Bloco F, Torre I, Ed. Premium, sala 14, SAF Sul. 70070-600 Brasília DF Brasil.

mfreitas.saude@gmail.com ${ }^{2}$ Faculdade de Medicina, Universidade Federal de

Ouro Preto.

${ }^{3}$ Departamento de Clínica

Médica, Faculdade de

Medicina, Universidade

Federal de Minas Gerais (UFMG).

${ }^{4}$ Departamento de Medicina Preventiva e Social, Faculdade de Medicina, UFMG.
Abstract The article aims to describe the profile of elderly victims of falls and traffic accidents from the data of the Surveillance Survey of Violence and Accidents (VIVA). The VIVA Survey was conducted in the emergency health-services of the Unified Health System in the capitals of Brazil in 2011. The sample of elderly by type of accident was subjected to the two-step cluster procedure. Of the 2463 elderly persons in question, $79.8 \%$ suffered falls and $20.2 \%$ were the victims of traffic accidents. The 1812 elderly who fell were grouped together into 4 clusters: Cluster 1, in which all had disabilities; Cluster 2, all were non-white and falls took place in the home; Cluster 3, younger and active seniors; and Cluster 4, with a higher proportion of seniors 80 years old or above who were white. Among cases of traffic accidents, 446 seniors were grouped into two clusters: Cluster 1 of younger elderly, drivers or passengers; Cluster 2, with higher age seniors, mostly pedestrians. The main victims of falls were women with low schooling and unemployed; traffic accident victims were mostly younger and male. Complications were similar in victims of falls and traffic accidents. Clusters allow adoption of targeted measures of care, prevention and health promotion.

Key words Health of the elderly, External causes, Traffic accidents, Accidental Falls, Health services for the elderly 


\section{Introduction}

In Brazil, there are 20.5 million individuals aged $\geq 60$ years, representing approximately $10.8 \%$ of the population, of whom $55.5 \%$ are women. The increased life expectancy at all ages, even among elderly people ${ }^{1}$, reflects advances and achievements but also demands the development of sustained public policies for the social inclusion of the elderly. Such policies are needed to ensure active aging, with autonomy, independence, access to information, security, health promotion, and disease prevention ${ }^{1,2}$.

It is the responsibility of the state and society to invest in a healthy lifestyle for this growing social group with specific needs. The strategies for health promotion include intersectoral actions aimed at creating supportive environments, including work and leisure. Among these, we highlight public spaces and urban infrastructure that meet the expectations and needs for improved quality of life and maintenance of the economically productive capacity, ${ }^{3,4}$. Ayres et al. propose evaluating the individual, social, and programmatic vulnerabilities to assess the characteristics of illnesses and mortality of distinct population groups. Social vulnerability involves aspects related to social risk, education, income, and labor; programmatic vulnerability involves aspects related to government investment actions and the degree and quality of engagement. Therefore, the process of health and disease is associated with individual aspects and with environmental factors and strategic resources.

National and international studies have shown the epidemiology of external causes such as abuse, accidents, traumas, and injuries among the elderly ${ }^{6-9}$. Violence and accidents represent a significant cause of morbidity (sixth-leading cause of hospitalization) and mortality (third-leading cause of death) in the general population ${ }^{10}$. With regard to environmental factors, Phillips et al. ${ }^{11}$ indicate that the combination of individual factors, e.g., reduced physical and cognitive ability, poor hearing and vision, combined with inadequate urban planning, have a negative impact on the mobility of the elderly as pedestrians and transportation users.

In other countries, elderly people classified as such often do not consider themselves old and therefore have no perception of the increased risk of accidents and injuries. In the elderly, falls are impactful events. This lack of awareness of their vulnerable situation can lead to increased risk of falls and should be properly managed by health care professionals to promote health and prevent accidents ${ }^{12}$. There is evidence that falls are common events and are more prevalent among women. Extrinsic environmental factors contributing to falls include the inadequacy of floors, lighting, stairs, bathrooms, and physical barriers in general. Intrinsic factors, including the use of medications - particularly benzodiazepines, antidepressants, and some antiarrhythmic drugs - add to these factors ${ }^{13}$. In addition, programs that provide information support and evaluation and stimulate daily activities are fundamental to healthy aging ${ }^{12}$.

This study aimed to describe the profile of elderly people according to information on traffic accidents and falls obtained from the Violence and Injury Surveillance System (Sistema de Vigilância de Violências e Acidentes - VIVA) in 2011. It also aimed to provide information to support public policies on comprehensive health care to prevent, treat, rehabilitate, and promote health in the elderly.

\section{Methods}

\section{VIVA survey}

The VIVA survey was a cross-sectional study conducted in urgent care and emergency services of the Unified Health System (SUS) in Brazilian capitals and the Federal District in 2011, with the exception of São Paulo and Manaus. The establishments that composed the study sample were selected on the basis of records obtained from the National Record of Health Units (Cadastro Nacional de Estabelecimentos de Saúde - CNES). Subsequently, these establishments were classified according to the number of health care services for external causes obtained from the Hospital Information System (Sistema de Informações Hospitalares - SIH) of SUS (SIH/SUS) and according to data from the VIVA surveys conducted in 2006, 2007, or 2009 (for health units participating in those years $)^{14}$. The units selected were reference centers in urgent and emergency care in each municipality and were validated by the surveillance team for non-communicable diseases (doenças e agravos não transmissíveis - DANT) in the State and Municipal Secretariats of Health of the respective participating municipalities ${ }^{14}$.

The study population were the victims of external causes (violence and accidents) who sought medical treatment in the units selected. The calculation of sample size, assuming a coef- 
ficient of variation of $<30 \%$ and standard error of $<3$, defined a minimum of 2000 health care services for external causes per municipality, regardless of the number of participating units. Data were collected during day and night shifts, lasting 12 hours each, for 30 consecutive days (between September and October 2011) using a standardized data collection form. The number of work shifts drawn for each establishment was calculated using the ratio of the minimum number of health care services for external causes (defined as 2000) to the average number of health care services for external causes in the same establishment in previous years ${ }^{14}$.

The random selection was conducted by single-stage cluster sampling, stratified by establishment, and the work shift was the primary sampling unit. All health care services for external causes performed in the selected shift were sampled. The health care services were classified as addressing violence or accidents according to the International Classification of Diseases (Classificação Internacional de Doenças - CID-10). The respondent was the victim or the responsible companion/guardian (in case the victim was under 18 years old or unable to answer the questions) $)^{14}$.

The forms were input into Epi Info software version 3.5.1 by the health surveillance team of each municipality and later transferred to the database of the Ministry of Health, which performed the consistency and duplicity analyse ${ }^{14}$. The 2011 VIVA survey was approved by the $\mathrm{Na}$ tional Research Ethics Committee (Comissão Nacional de Ética em Pesquisa - CONEP) of the Ministry of Health.

\section{Two-step cluster method and variables used}

The two-step cluster method has an exploratory nature. It has been used to identify natural groups of cases or individuals in large databases and is very effective in these situations. This method allows for the identification of groups using quantitative and qualitative variables (clusters) and continuous or categorical/ordinal variables and automatically calculates the number of empirical clusters on the basis of Bayesian and Akaike information criteria, which are used jointly and comparatively to empirically provide the optimal solution ${ }^{15}$.

We implemented a two-step clustering algorithm in SPSS software ${ }^{16}$. The qualitative variables were categorized on the basis of the literature. Later, these variables were used with the option for determining whether they were qualitative or quantitative (continuous or categorical). According to Shih et al. ${ }^{16}$, an algorithm that automatically recategorizes the most common variables is feasible, but this option has not been incorporated into the SPSS software.

The analysis was conducted separately for two groups: elderly people who were victims of falls and victims of traffic accidents. For cluster formation, the variables that could define groups for which interventions could be made to prevent falls and traffic accidents were used. Therefore, for the definition of clusters containing fall and traffic accident victims, the following sociodemographic variables were selected: age (continuous), gender (female, male), ethnicity (white, non-white), schooling (0-4 years, 5-8 years, 9-11 years, $>12$ years), work status (employed or not at the date of occurrence), whether the occurrence was related to work (yes, no), and the event location (urban, rural, or peri-urban). The vulnerability variable was used when the victim had a permanent disability on the date of the occurrence (yes, no). With regard to the circumstantial aspects of the event, we used the day of the week (Sunday to Saturday; seven categories) and whether the patient had consumed alcohol within six hours before the occurrence (yes, no). With regard to severity, the variables used were the nature of the injury (no injury, occurrence of bruises, cuts/lacerations, sprains/dislocations, fractures, etc.) and the outcome within 24 hours (discharge, admission, outpatient referral, indication to another service, death, etc.).

To create clusters of fall victims, the variables associated with the circumstance, place of occurrence (public road, residence, etc.), and type of fall (relative to victim's own height, hole, bed, furniture, scaffolding, ladder/step, tree, roof/slab, other levels) were used. To create clusters of accident victims, we used the variables type of victim (pedestrian, driver, or passenger) and objects involved other than the victim (car, motorcycle, bus/minibus, bicycle, other).

The clusters formed within each of the two groups were compared using Student's t test or the analysis of proportion differences (chi-squared test or Fisher's exact test) for each selected variable. Elderly people not allocated to any cluster were compared with those who were grouped using this cluster method. The significance level selected was $5 \%$. The percentages presented were based on the total number of responses for each question and not the total number of cases investigated, considering the existence of undeclared 
values. In addition, when detailing the data in the results tables, broader categories were created depending on the similarity of these categories with each other in the clusters formed. The data were processed using SPSS software version 19.0 and Stata software version 6.0.

To apply the clustering method, all assumptions were met. The criteria used for selecting the number of clusters was the Bayesian information criterion (BIC), and the distance measure used was the log-likelihood distance. Both BIC and distance were the default options in the SPSS software. Furthermore, the available sample weights were not used, considering that the application of the clustering method does not allow the incorporation of weights ${ }^{17}$. The assumptions included the use of variables with binomial or multinomial distribution and independence between the variables. However, even if these assumptions existed, the SPSS algorithm was robust to small violations of these assumptions ${ }^{18}$. The technical limitations included severe violations of the assumptions and the difficulty of finding patterns in a sample in which individuals are very heterogeneous (high degree of entropy) ${ }^{16}$.

Naming the clusters was a subjective process. However, attempts were made to standardize the names assigned to each cluster so that they would represent the most significant findings and guide the reader in understanding the main characteristics demarcated by the empirically obtained groups.

\section{Results}

\section{General Information about the Sample Analyzed}

The study sample included 2463 elderly people, of whom 1965 (79.8\%) experienced falls and $498(20.2 \%)$ were victims of traffic accidents. The two-step cluster analysis revealed four clusters of fall victims and two clusters of traffic accident victims. Both analyses indicated that part of the study sample could not be clustered in either of the two groups, and these individuals were designated the unclassified group.

\section{Fall victims}

Among the elderly people grouped using the two-step cluster method ( $92.8 \%$ of the 1965 subjects), the average age was $73 \pm 9.5$ years, the median age was 72 (IQR: $65 ; 79$ ), and $42.9 \%$ of the study population was aged 60-69 years (Table 1). Most were women $(62.6 \%)$, of non-white ethnicity $(56.3 \%)$, with fewer than 5 years of schooling (64.9\%), and most of the accidents occurred in urban areas (91.7\%). Moreover, $17.9 \%$ of the study sample were employed, and $6.9 \%$ experienced work-related falls; $12.1 \%$ had some disability, the most common of which was visual disability $(4.7 \%)$ followed by physical disability $(4.3 \%) ; 4.1 \%$ of the study population consumed alcohol, and $26.5 \%$ of these cases occurred during the weekend, most often in the morning or afternoon $(69.6 \%)$ and in the victim's residence $(74.1 \%) ; 65.1 \%$ of the elderly experienced falls from their own height. Bruises and fractures were the most common injuries $(26.9 \%$ and $22.0 \%$, respectively). The most frequent outcome in emergencies was hospital discharge (71.1\%).

The unclassified group included 153 elderly people $(7.8 \%)$. The frequencies of any disability, mental disability, other disability, alcohol use, and hospitalization were significantly higher for elderly people in this group compared with the two-step clustered groups $(p<0.05)$. No other significant differences were observed between the groups.

In the analysis of groups assigned to each cluster, the individuals in cluster 1 had a mean age (SD) of 75.1 (9.4) years and median age (IQR) of $74.5(67 ; 82)$ years. Most were aged 7079 years. In addition, $56.2 \%$ were women, 50\% were of non-white ethnicity, $73.9 \%$ had fewer than 5 years of schooling, $8.6 \%$ were employed at the time of the occurrence, and $4 \%$ of falls were associated with work (Table 2). All participants had at least one disability, and $2.7 \%$ had recently consumed alcohol. In addition, $80.6 \%$ of the falls occurred in the residence, $58.7 \%$ were from the victim's own height, and $18.6 \%$ were from the bed or furniture. Bruises, fractures, and cuts/ lacerations occurred in $27.0 \%, 20.8 \%$, and $19.5 \%$ of the study population, respectively. In addition, $66.4 \%$ and $18.6 \%$ of the study group were discharged and admitted to the hospital, respectively. This cluster, designated elderly people with disabilities, represented $12.5 \%(\mathrm{n}=216)$ of the total number of fall victims who were assigned to clusters.

Individuals from cluster 2 were younger than those from cluster 1, and most were aged 60-69 years $(40.5 \%)$ (Table 2). The proportion of women was higher $(65.9 \%)$. All were of non-white ethnicity, with a lower percentage of individuals with fewer than 5 years of schooling $(70.7 \%)$ and a higher percentage of individuals who were 
Table 1. Number and percentage of elderly victims of falls in the unclassified group (without profile) and those allocated to clusters (with profile) - VIVA survey 2011.

\begin{tabular}{|c|c|c|c|}
\hline Variable & $\begin{array}{l}\text { Without profile } \\
\qquad n=153\end{array}$ & $\begin{array}{l}\text { With profile } \\
\quad n=1812\end{array}$ & p value \\
\hline Age $($ mean $\pm S D)$ & $73.3 \pm 9.4$ & $73.0 \pm 9.5$ & 0.764 \\
\hline Median age (IQR) & $72.0(65-79)$ & $72.0(65-79)$ & 0.683 \\
\hline Age groups & & & 0.245 \\
\hline $60-69$ & $57(37.3)$ & $777(42.9)$ & \\
\hline $70-79$ & $59(38.3)$ & $584(32.2)$ & \\
\hline$\geq 80$ & $37(24.2)$ & $451(24.9)$ & \\
\hline Female & $92(61.3)$ & $1134(62.6)$ & 0.761 \\
\hline Non-white ethnicity & $77(55.0)$ & $1019(56.3)$ & 0.997 \\
\hline Schooling (years) & & & 0.120 \\
\hline $0-4$ & $71(55.5)$ & $1107(64.9)$ & \\
\hline $5-8$ & $34(26.6)$ & $323(18.9)$ & \\
\hline $9-11$ & $19(14.8)$ & $213(12.5)$ & \\
\hline$>12$ & $4(13.1)$ & $63(3.7)$ & \\
\hline Currently employed & $28(20.0)$ & $318(17.9)$ & 0.529 \\
\hline Work-related falls & $8(7.6)$ & $125(6.9)$ & 0.778 \\
\hline Place of occurrence & & & 0.161 \\
\hline Urban & $134(95.0)$ & $1661(91.7)$ & \\
\hline Rural & $4(2.8)$ & $123(6.8)$ & \\
\hline Peri-urban & $3(2.1)$ & $27(1.5)$ & \\
\hline \multicolumn{4}{|l|}{ Presence of disabilities } \\
\hline Any & $37(26.4)$ & $218(12.1)$ & $<0,001^{*}$ \\
\hline Physical & $10(7.9)$ & $77(4.3)$ & 0.077 \\
\hline Mental & $7(5.6)$ & $33(1.8)$ & $0.015^{*}$ \\
\hline Visual & $5(4.0)$ & $84(4.7)$ & 0.078 \\
\hline Hearing & $6(4.9)$ & $41(2.3)$ & 0.185 \\
\hline Others & $4(3.3)$ & $9(0.5)$ & $0,001^{*}$ \\
\hline Alcohol use & $19(13.7)$ & $75(4.1)$ & $<0,001^{*}$ \\
\hline Occurrence on Saturday or Sunday (weekend) & $45(31.5)$ & $480(26.5)$ & 0.196 \\
\hline Period of occurrence & & & 0.188 \\
\hline Morning or afternoon & $105(71.0)$ & $1261(69.6)$ & \\
\hline Night & $36(20.9)$ & $456(25.2)$ & \\
\hline Dawn & $19(12.4)$ & $95(5.2)$ & \\
\hline Location & & & 0.109 \\
\hline Residence & $102(66.7)$ & $1342(74.1)$ & \\
\hline Public places & $32(20.9)$ & $315(17.4)$ & \\
\hline Others & $19(12.4)$ & $155(8.6)$ & \\
\hline Type of fall & & & 0.065 \\
\hline Own height & $111(74.0)$ & $1178(65.1)$ & \\
\hline Bed or other furniture & $13(8.7)$ & $237(13.1)$ & \\
\hline Ladder or step & $11(7.3)$ & $231(12.8)$ & \\
\hline Others & $15(10.0)$ & $164(9.1)$ & \\
\hline Nature of the injury & & & 0.522 \\
\hline No injury & $7(4.6)$ & $83(4.6)$ & \\
\hline Contusion & $44(28.8)$ & $487(26.9)$ & \\
\hline Cut/laceration & $34(22.2)$ & $339(18.7)$ & \\
\hline Sprain/dislocation & $19(12.4)$ & $328(18.1)$ & \\
\hline Fracture & $30(19.6)$ & $399(22.0)$ & \\
\hline Trauma & $17(11.1)$ & $154(8.5)$ & \\
\hline Other & $2(1.3)$ & $22(1.2)$ & \\
\hline Outcome during emergency & & & $0.002^{*}$ \\
\hline Hospital discharge & $87(64.4)$ & $1280(71.1)$ & \\
\hline Hospital admission & $32(23.7)$ & $286(15.9)$ & \\
\hline Other & $16(11.9)$ & $234(13.0)$ & \\
\hline
\end{tabular}

Note: For comparisons between the groups with and without profile, Fisher's exact test was used for the following variables: schooling, area of occurrence, presence of deficiencies, and nature of the injury. ${ }^{*} \mathrm{p}<0.05$ 
Table 2. Number and percentage of older elderly victims of falls who were allocated into clusters (with profile) - VIVA Survey 2011.

\begin{tabular}{|c|c|c|c|c|c|c|}
\hline Variable & $\begin{array}{c}\text { Total } \\
\mathrm{n}=1812\end{array}$ & $\begin{array}{c}\text { Cluster } 1 \\
\mathrm{n}=216\end{array}$ & $\begin{array}{c}\text { Cluster } 2 \\
n=618\end{array}$ & $\begin{array}{c}\text { Cluster } 3 \\
\mathrm{n}=488\end{array}$ & $\begin{array}{c}\text { Cluster } 4 \\
\mathrm{n}=480\end{array}$ & $\begin{array}{c}\text { p-value } \\
(\text { Compares } \\
\text { clusters } 1 \text { to } 4)\end{array}$ \\
\hline Age $($ mean $\pm S D)$ & $73.0 \pm 9.5$ & $75.1 \pm 9.4$ & $73.2 \pm 9.5$ & $69.7 \pm 8.2$ & $75.1 \pm 9.9$ & $<0.001^{*}$ \\
\hline Median age (IQR) & $72.0(65-79)$ & $74.5(67-82)$ & $72.0(65-79)$ & $68.0(63-75)$ & $74.5(67-82.5)$ & $<0.001^{*}$ \\
\hline Age groups & & & & & & $<0.001^{*}$ \\
\hline $60-69$ & 777 (42.9) & $74(32.7)$ & $250(40.5)$ & $282(57.8)$ & $171(35.6)$ & \\
\hline $70-79$ & $584(32.2)$ & $81(35.8)$ & $219(35.4)$ & $140(28.7)$ & $144(30.0)$ & \\
\hline$\geq 80$ & $451(24.9)$ & $71(31.4)$ & $149(24.1)$ & $66(13.5)$ & $165(34.4)$ & \\
\hline Female & $1134(62.6)$ & $127(56.2)$ & 407 (65.9) & $259(53.1)$ & $341(71.0)$ & $<0.001^{*}$ \\
\hline Non-white ethnicity & $1019(56.3)$ & $113(50.0)$ & $618(100.0)$ & $288(59.0)$ & $0(0.0)$ & $<0.001^{*}$ \\
\hline Schooling (years) & & & & & & $<0.001^{*}$ \\
\hline $0-4$ & $1107(64.9)$ & $150(73.9)$ & $413(70.7)$ & $255(55.4)$ & $289(63.0)$ & \\
\hline $5-8$ & $323(18.9)$ & $32(15.8)$ & $117(20.0)$ & $104(22.6)$ & $72(15.3)$ & \\
\hline $9-11$ & $213(12.5)$ & $13(6.4)$ & $48(8.2)$ & $75(16.3)$ & $77(16.8)$ & \\
\hline$>12$ & $63(3.7)$ & $8(3.9)$ & $6(1.0)$ & $26(5.7)$ & $23(5.0)$ & \\
\hline Currently employed & 318 (17.9) & $19(8.6)$ & $93(15.3)$ & $161(33.8)$ & $45(9.5)$ & $<0.001^{*}$ \\
\hline Work-related falls & $125(6.9)$ & $9(4.0)$ & $24(3.9)$ & $86(17.6)$ & $6(1.3)$ & $<0.001^{*}$ \\
\hline Place of occurrence & & & & & & 0.171 \\
\hline Urban & $1661(91.7)$ & $213(94.3)$ & $561(90.8)$ & $436(89.5)$ & $451(94.0)$ & \\
\hline Rural & $123(6.8)$ & $11(4.9)$ & $47(7.6)$ & $41(8.4)$ & $24(5.0)$ & \\
\hline Peri-urban & $27(1.5)$ & $2(0.9)$ & $10(1.6)$ & $10(2.1)$ & $5(1.0)$ & \\
\hline \multicolumn{7}{|l|}{ Presence of disabilities } \\
\hline Any & $218(12.1)$ & $216(100.0)$ & $1(0.2)$ & $1(0.2)$ & $0(0.0)$ & $<0.001^{*}$ \\
\hline Physical & $77(4.3)$ & $76(35.7)$ & $1(0.2)$ & $0(0.0)$ & $0(0.0)$ & $<0.001^{*}$ \\
\hline Mental & $33(1.8)$ & $33(15.4)$ & $0(0.0)$ & $0(0.0)$ & $0(0.0)$ & $<0.001^{*}$ \\
\hline Visual & $84(4.7)$ & $83(38.8)$ & $0(0.0)$ & $1(0.2)$ & $0(0.0)$ & $<0.001^{*}$ \\
\hline Hearing & $41(2.3)$ & $41(19.3)$ & $0(0.0)$ & $0(0.0)$ & $0(0.0)$ & $<0.001^{*}$ \\
\hline Others & $9(0.5)$ & $9(3.8)$ & $0(0.0)$ & $0(0.0)$ & $0(0.0)$ & \\
\hline Alcohol use & $75(4.1)$ & $6(2.7)$ & $2(0.3)$ & $63(12.9)$ & $4(0.8)$ & $<0.001^{*}$ \\
\hline Occurrence on Saturday or Sunday & $480(26.5)$ & $62(27.4)$ & $174(28.2)$ & $112(23.0)$ & $132(27.5)$ & 0.224 \\
\hline Period of occurrence & & & & & & 0.188 \\
\hline Morning/afternoon & $1261(69.6)$ & $154(68.1)$ & $451(73.0)$ & $329(67.4)$ & $327(68.1)$ & \\
\hline Night & $456(25.2)$ & $55(24.3)$ & $137(22.2)$ & $132(27.1)$ & $132(27.5)$ & \\
\hline Dawn & $95(5.2)$ & $17(7.5)$ & $30(4.9)$ & $27(5.5)$ & $21(4.4)$ & \\
\hline Location & & & & & & $<0.001^{*}$ \\
\hline Residence & $1342(74.1)$ & $182(80.6)$ & $618(100.0)$ & $62(12.7)$ & $480(100.0)$ & \\
\hline Public places & $315(17.4)$ & $30(13.3)$ & $0(0.0)$ & $285(58.4)$ & $0(0.0)$ & \\
\hline Others & $155(8.6)$ & $14(6.2)$ & $0(0.0)$ & $141(28.9)$ & $0(0.0)$ & \\
\hline Type of fall & & & & & & $<0.001^{*}$ \\
\hline Own height & $1178(65.1)$ & $132(58.7)$ & $380(61.6)$ & $336(68.9)$ & $330(68.8)$ & \\
\hline Bed or other furniture & $237(13.1)$ & $41(18.2)$ & $109(17.7)$ & $10(2.1)$ & $77(16.0)$ & \\
\hline Ladder & $231(12.8)$ & $33(14.7)$ & $84(13.6)$ & $58(11.9)$ & $56(11.7)$ & \\
\hline Others & $164(9.1)$ & $19(8.4)$ & $44(7.1)$ & $84(17.2)$ & $17(3.5)$ & \\
\hline Nature of the injury & & & & & & $<0.001^{*}$ \\
\hline No injury & $83(4.6)$ & $8(3.5)$ & $20(3.2)$ & $47(9.6)$ & $8(1.7)$ & \\
\hline Contusion & 487 (26.9) & $61(27.0)$ & $192(31.1)$ & $115(23.6)$ & $119(24.8)$ & \\
\hline Cut/laceration & $339(18.7)$ & $44(19.5)$ & $89(14.4)$ & $110(22.5)$ & $96(20.0)$ & \\
\hline Sprain/dislocation & $328(18.1)$ & $40(17.7)$ & $118(19.1)$ & $87(17.8)$ & $83(17.3)$ & \\
\hline Fracture & $399(22.0)$ & $47(20.8)$ & $134(21.7)$ & $92(18.9)$ & $126(26.3)$ & \\
\hline Trauma & $154(8.5)$ & $26(11.5)$ & $56(9.1)$ & $30(6.2)$ & $42(8.8)$ & \\
\hline Other & $22(1.2)$ & $0(0.0)$ & $9(1.5)$ & $7(1.4)$ & $6(1.3)$ & \\
\hline Outcome during emergency & & & & & & $0.001^{*}$ \\
\hline Hospital discharge & $1280(71.1)$ & $150(66.4)$ & $437(71.2)$ & $376(77.3)$ & $316(66.3)$ & \\
\hline Hospital admission & $286(15.9)$ & $42(18.6)$ & $92(15.0)$ & $54(11.4)$ & $98(20.6)$ & \\
\hline Other & $234(13.0)$ & $34(15.0)$ & $85(13.8)$ & $52(10.8)$ & $63(13.2)$ & \\
\hline
\end{tabular}

Note: For comparisons between clusters 1 to 4, Fisher's exact test was used for the following variables: place of occurrence, presence of deficiencies, location and nature of the injury. ${ }^{*} \mathrm{p}<0.05$ 
employed at the time of the occurrence (15.6\%). Only one subject showed a disability in this group, and there was virtually no involvement of alcohol $(0.3 \%)$. All of the elderly people experienced falls in the residence. The nature of the injury involved bruises for a higher percentage of elderly people (31.1\%), and cuts/lacerations for a lower percentage (14.4\%). Fractures were experienced by a higher percentage of elderly people (21.7\%) compared with subjects from cluster 1 . Moreover, $71.2 \%$ and $15.0 \%$ of the study population were discharged and admitted to the hospital, respectively. This cluster, designated elderly people of non-white ethnicity experiencing falls in their residence, included $34.1 \%(n=618)$ of the 1812 subjects classified.

Individuals from cluster 3 were the youngest, with $>50 \%$ aged $60-69$ years, with a lower percentage of women and more schooling on average (Table 2). A higher percentage of subjects in this cluster were employed, so the frequency of work-related falls was higher. The percentage of alcohol use and falls in public places was the highest in this cluster, and a lower percentage of falls occurred from the bed or other furniture than in other clusters. The frequency of individuals without injury was the highest among the clusters evaluated, with an even higher percentage of those who were discharged from hospital. This group was designated the young and active elderly ( $n=488 ; 26.9 \%)$.

Compared with the other clusters, cluster 4 had the highest percentage of the oldest elderly - subjects aged $\geq 80$ years - and the highest percentage of women, with all individuals of white ethnicity, and the lowest percentage of work-related falls. All falls occurred in the residence, and no subjects had disabilities. This group had the lowest percentage of individuals without lesions and the highest percentage of individuals with fractures. In addition, this group had the highest percentage of hospital admissions and the lowest percentage of hospital discharges. Group 4 was designated the oldest elderly of white ethnicity (n $=480 ; 26.5 \%$ ).

\section{Elderly people victims of traffic accidents}

Of the 498 elderly victims of traffic accidents, 446 (89.6\%) were grouped into clusters, and 52 were not grouped (10.4\%) (unclassified group) (Table 3). The mean age of the 446 clustered individuals was $68.5 \pm 7.2$ years. The median age was 66 years (IQR: 63; 73). Most individuals were aged $60-69$ years $(62.3 \%)$, and $39.5 \%$ were wom- en; most were of non-white ethnicity $(64.8 \%)$, with fewer than 5 years of schooling $(60.5 \%)$, and most accidents occurred in urban areas $(83.1 \%)$. On the date of the occurrence, $34.3 \%$ were employed and $14.3 \%$ of the cases involved work-related accidents; $6.4 \%$ of the individuals in this group had disabilities; $6.1 \%$ of this group had consumed alcohol. In addition, $24.1 \%$ of the accidents occurred on the weekend (Saturdays and Sundays), predominantly in the morning or the afternoon $(65.0 \%)$. Most of the victims were pedestrians or drivers $(37.8 \%$ and $34.8 \%$, respectively), and $33.8 \%$ of the accidents involved cars, while $26.4 \%$ involved motorcycles. Cuts/lacerations, bruises, and trauma were the most common injuries $(25.3 \%, 23.7 \%$, and $18.1 \%$, respectively). The most frequent outcome was hospital discharge $(63.5 \%)$.

The percentage of elderly people with up to 4 years of schooling was significantly lower in the unclassified group compared with the clustered groups $(p<0.05)$. Alcohol involvement was higher in the unclassified group $(\mathrm{p}<0.05)$ compared with the other groups. No significant differences were observed for the other variables (Column 3, Table 3).

With regard to the clusters formed, elderly people from cluster 1 had a mean age (SD) of 67.4 (6.9) years and median age (IQR) of 65.0 (62; 71) years; $69.5 \%$ were aged $60-69$ years, $32.3 \%$ were women, $65.7 \%$ were of non-white ethnicity, $58.0 \%$ had fewer than 5 years of schooling, and $76.4 \%$ of the traffic accidents occurred in urban areas. Furthermore, $40.5 \%$ of the group was employed at the time, $18.4 \%$ of the accidents were related to work, $7.5 \%$ of the group had at least one disability, and 5.7\% had consumed alcohol. Only four individuals were pedestrians, and $55.4 \%$ were drivers. A fixed object or animal was involved in $51.9 \%$ of the cases. Cuts/lacerations, bruises, fractures, and trauma occurred in $27.0 \%$, $25.5 \%, 15.6 \%$, and $15.6 \%$ of the subjects, respectively, and $68.6 \%$ were discharged from hospital. This group was named the young and active elderly people, drivers or passengers and represented $62.3 \%(n=282)$ of the elderly who were victims of traffic accidents and were assigned to clusters.

Individuals from cluster 2 were older than those from cluster 1 and 50\% were aged $\geq 70$ years. The frequency of women was higher in this group $(51.8 \%), 63.4 \%$ of the sample were non-white, only $23.2 \%$ were employed, and $7.0 \%$ were involved in work-related accidents. All were pedestrians except for one individual. Cars or 
Table 3. Number and percentage of elderly victims of traffic accidents in the unclassified group (without profile) and those allocated to clusters (with profile) - VIVA survey 2011.

\begin{tabular}{|c|c|c|c|c|c|c|}
\hline Variable & $\begin{array}{c}(1) \\
\text { Without profile } \\
\mathrm{n}=52\end{array}$ & $\begin{array}{c}\quad(2) \\
\text { With profile } \\
n=446\end{array}$ & $\begin{array}{c}(3) \\
\text { p-value } \\
\text { between }(1) \text { and }(2)\end{array}$ & $\begin{array}{c}(4) \\
\text { Cluster } 1 \\
n=282\end{array}$ & $\begin{array}{c}(5) \\
\text { Cluster } 2 \\
\mathrm{n}=164\end{array}$ & $\begin{array}{r}\text { p-value } \\
\text { between } \\
\text { (4) and (5) }\end{array}$ \\
\hline Age & & & 0.610 & & & \\
\hline mean $(\mathrm{SD})$ & $68(6.9)$ & $68.5 \pm 7.2$ & & $67.4 \pm 6.9$ & $70.5 \pm 7.1$ & $<0.001^{*}$ \\
\hline median (IQR) & $66.0(62-72)$ & $66.0(63-73)$ & & $65.0(62-71)$ & $69.5(65-75.5)$ & $<0.001^{*}$ \\
\hline Age groups & & & 0.388 & & & $<0.001^{*}$ \\
\hline $60-69$ & $39(70.9)$ & $278(62.3)$ & & $196(69.5)$ & $82(50.0)$ & \\
\hline $70-79$ & $13(23.6)$ & $124(27.8)$ & & $66(23.4)$ & $58(35.4)$ & \\
\hline$\geq 80$ & $3(5.5)$ & $44(9.9)$ & & $20(7.1)$ & $24(14.6)$ & \\
\hline Female & $36(30.8)$ & $176(39.5)$ & 0.223 & $91(32.3)$ & $85(51.8)$ & $<0.001^{*}$ \\
\hline Non-white ethnicity & $30(57.6)$ & $282(64.8)$ & 0.311 & $180(65.7)$ & $102(63.4)$ & $<0.622$ \\
\hline Schooling (years) & & & $0.035^{*}$ & & & 0.412 \\
\hline $0-4$ & $16(41.0)$ & $250(60.5)$ & & $156(58.0)$ & $94(62.3)$ & \\
\hline $5-8$ & $12(30.8)$ & $75(18.2)$ & & $19.0 \pm 15.8$ & $24(16.7)$ & \\
\hline $9-11$ & $10(25.6)$ & $62(15.0)$ & & $42(15.6)$ & $20(13.9)$ & \\
\hline$>12$ & $1(2.6)$ & $26(6.3)$ & & $20(7.4)$ & $6(4.2)$ & \\
\hline Currently employed & $20(42.6)$ & $147(34.3)$ & 0.258 & $111(40.5)$ & $36(23.2)$ & $<0.001^{*}$ \\
\hline Work-related transport accident & $4(8.9)$ & $62(14.3)$ & 0.320 & $51(18.4)$ & $11(7.0)$ & $0.001^{*}$ \\
\hline \multicolumn{7}{|l|}{ Occurrence zone } \\
\hline Urban & $46(83.6)$ & $369(83.1)$ & 0.367 & $214(76.4)$ & 155 (94.5) & $<0.001^{*}$ \\
\hline Rural & $8(14.6)$ & $49(11.0)$ & & $43(15.4)$ & $6(3.7)$ & \\
\hline Peri-urban & $1(1.8)$ & $26(5.9)$ & & $23(8.2)$ & $3(1.8)$ & \\
\hline Presence of disabilities & $2(4.0)$ & $28(6.4)$ & 0.511 & $21(7.5)$ & $7(4.4)$ & 0.191 \\
\hline Alcohol use & $7(16.3)$ & $27(6.1)$ & $0.012^{*}$ & $16(5.7)$ & $11(6.7)$ & 0.659 \\
\hline Occurrence on Saturday or Sunday & $17(32.7)$ & $68(24.1)$ & 0.158 & $38(23.2)$ & $106(23.8)$ & 0.822 \\
\hline Period of occurrence & & & 0.665 & & & 0.640 \\
\hline Morning or afternoon & $33(60.0)$ & $290(65.0)$ & & $181(64.2)$ & $109(66.5)$ & \\
\hline Night & $19(34.6)$ & $128(28.7)$ & & $81(28.7)$ & $47(28.7)$ & \\
\hline Dawn & $3(5.5)$ & $28(6.3)$ & & $20(7.1)$ & $8(4.9)$ & \\
\hline Type of Victim & & & 0.881 & & & $<0.001^{*}$ \\
\hline Pedestrian & $20(58.8)$ & $167(37.8)$ & & $4(1.4)$ & $163(99.4)$ & \\
\hline Driver & $16(35.3)$ & $154(34.8)$ & & $154(55.4)$ & $0(0.0)$ & \\
\hline Passenger & $15(5.9)$ & $121(27.4)$ & & $120(43.2)$ & $1(0.6)$ & \\
\hline Object involved other than the victim & & & 0.438 & & & $<0.001^{*}$ \\
\hline Car & $10(30.3)$ & $146(33.8)$ & & $77(28.7)$ & $69(42.1)$ & \\
\hline Motorcycle & $12(36.4)$ & $114(26.4)$ & & $40(14.9)$ & $74(45.1)$ & \\
\hline Bus/minibus & $0(0.0)$ & $14(3.2)$ & & $6(2.2)$ & $8(4.9)$ & \\
\hline Bicycle & $0(0.0)$ & $19(4.4)$ & & $6(2.2)$ & $13(7.9)$ & \\
\hline Other & $11(3.3)$ & $139(32.2)$ & & $199(51.9)$ & $0(0.0)$ & \\
\hline Nature of the injury & & & 0.378 & & & 0.355 \\
\hline No injury & $2(3.9)$ & $13(2.9)$ & & $10(3.6)$ & $3(1.9)$ & \\
\hline Contusion & $11(21.6)$ & $105(23.7)$ & & $72(25.5)$ & $33(20.5)$ & \\
\hline Cut/laceration & $9(17.7)$ & $112(25.3)$ & & $76(27.0)$ & $36(22.4)$ & \\
\hline Sprain/dislocation & $10(19.6)$ & $52(11.7)$ & & $31(11.0)$ & $21(13.0)$ & \\
\hline Fracture & $6(11.8)$ & $74(16.7)$ & & $44(15.6)$ & $30(18.6)$ & \\
\hline Trauma & $13(25.5)$ & $80(18.1)$ & & $44(15.6)$ & $36(22.4)$ & \\
\hline Other & $0(0.0)$ & $7(1.6)$ & & $0(1.8)$ & $9(1.2)$ & \\
\hline Outcome during emergency & & & 0.281 & & & $0.011^{*}$ \\
\hline Hospital discharge & $26(54.2)$ & $278(63.5)$ & & $190(68.6)$ & $88(54.7)$ & \\
\hline Hospital admission & $12(25.0)$ & $94(21.5)$ & & $52(18.8)$ & $42(26.1)$ & \\
\hline Number of deaths & $2(4.2)$ & $5(1.1)$ & & $1(0.4)$ & $4(2.5)$ & \\
\hline Other & $8(16.7)$ & $61(13.9)$ & & $34(12.3)$ & $27(16.8)$ & \\
\hline
\end{tabular}

Note: For comparisons between the groups with and without profile, Fisher's exact test was used for the following variables: age, age group, schooling, work-related transport accident, place of occurrence, time of occurrence, nature of injury, and outcome during emergency. For comparisons between profiles 1 and 2, Fisher's exact test was used for the following variables: place of occurrence, type of victim, object involved other than the victim, nature of the injury, and outcome during emergency. ${ }^{*} \mathrm{p}<0.05$ 
motorcycles were involved in $42.1 \%$ or $45.1 \%$ of the traffic accidents, respectively. Cuts/lacerations, trauma, bruises, and fractures occurred in $22.4 \%, 22.4 \%, 20.5 \%$, and $18.6 \%$ of the subjects, respectively. In addition, $54.7 \%$ of the individuals in this group were discharged from hospital. This cluster was designated the oldest elderly, pedestrians, with more severe outcomes and represented $37.7 \%(n=164)$ of those allocated into clusters.

\section{Discussion}

External causes are represented primarily by falls and traffic accidents and are considered important determinants of morbidity and mortality among elderly people. For decades, falls have been recognized by health professionals as a lesion etiology ${ }^{19,20}$. However, more recently, they have been included as an independent marker of frailty, particularly among elderly people ${ }^{20}$.

The impact of falls can be quite severe. There is evidence of an indirect association between high mortality and fall-related injuries that can last for a long time after treatment of the outcomes ${ }^{21}$. In addition, more than $50 \%$ of elderly people who have experienced a fall develop the fear of falling again (ptophobia), with consequent physical inactivity, worsening of balance, and increased risk of additional falls. Fall-related accidents account for $40 \%$ of the events that lead to hospitalization of elderly people ${ }^{22}$. Therefore, they are considered a health problem, and some scholars consider them a unique geriatric syndrome ${ }^{23}$.

In the analyzed sample, the frequency of complications due to falls (or presence of lesions) was higher than previously reported ${ }^{12,24}$, and the incidence of falls was 95\% most likely because the target population sought urgent or emergency medical care.

The unclassified group, although they were not allocated to any particular cluster using statistical procedures, included many individuals at risk and who had permanent disabilities and severe outcomes that should be acknowledged for the design of specific public policies. This group had a higher risk of hospitalization, which in turn was associated with functional decline and disability $^{25}$.

With regard to cluster 1 , our results indicate that falls occurred predominantly in the residence (>80\%). For this group, interventions aimed at rehabilitation and at increased accessibility to mitigate the effects of disability are essential.
With respect to cluster 2, all fall accidents occurred in the residence and were not associated with work, highlighting the importance of interventions aimed at the safety of elderly people in their residence ${ }^{26}$. A recent study that evaluated the home environment in Brazil indicated that the more frequent risks of falling in descending order were the absence of handle bars in the bathroom, the presence of carpets, the presence of steps, the absence of non-slip carpets in the bathroom, and difficulty in accessing the light switch $^{26}$.

In cluster 3, the highest percentage of falls from the victims' own height was observed. In fact, falls from one's own height are considered a public health problem because of their high frequency and direct and indirect effects on health ${ }^{27}$. They occur primarily among elderly people but can also occur in epileptics, chronic alcoholics, and drug addicts. They can cause major injuries and injuries that can result in imminent risk of death, and they can worsen previous morbid states $^{27}$. Notably, with the increased longevity of elderly people, pre-existing conditions that predispose to falls from own height can increase with age. Therefore, prospectively, this event should become increasingly frequent ${ }^{26}$. The analysis of this cluster indicated that it is necessary to resort to multidisciplinary resources for the health care of elderly people-particularly those with diseases that limit their autonomy-to understand the specifics of aging.

The group with the greatest risk of complications was cluster 4 , especially considering the risk of increased frailty in these individuals. They represented more than $25 \%$ of the sample and, in view of the progressively aging population, constituted a group that will be increasingly prevalent in the population over time. The falls more commonly associated with complications occurred in the victim's residence, were associated with neither the use of alcohol nor with work accidents, and occurred predominantly from the victim's own height. Accordingly, special attention should be given to the planning of care services for this age group, including home care, in view of the high risk of fractures and injuries in general.

By contrast, the group that included traffic accident victims was younger, of the male gender, with less schooling, and these accidents occurred in urban areas. Because they were younger, $>40 \%$ were employed, only $6.4 \%$ had disabilities, and most traffic accidents occurred during the day. The clusters were very well demarcated. Young- 
er elderly, active, drivers or passengers (cluster 1) were composed predominantly of men.

Cluster 2 included the oldest elderly, pedestrians, those with more severe outcomes, and consisted of men and women in equal proportions. In both clusters, a high prevalence of traffic accidents involving motorcycles was observed, especially among elderly pedestrians. Although traffic accidents are considered preventable causes this type of accident is increasingly common in Brazil, especially motorcycle accidents, which have been gradually increasing ${ }^{10,28}$.

The analysis of cluster 2 indicates the increased risk of being run over among elderly people with more advanced age. Among the traffic accidents, being run over is the principal cause of death for this group ${ }^{28}$. This is due to decreased reflexes, agility, and strength that gradually occur with the aging process, combined with the increased prevalence of chronic diseases and polypharmacy for treatment of comorbidities ${ }^{29}$.

The prevalence of complications was similar among the groups who were victims of falls and traffic accidents. Understanding this reality is fundamental because the risk of complications from falls from one's own height is similar to the risk of complications from traffic accidents. Therefore, the risk of falls should not be underestimated, and even in the context of the ever-increasing number of traffic accidents in Brazil, the risk should not be relativized. In fact, the incidence of fractures was higher for falls than for traffic accidents.

In routine visits to health professionals, elderly people should be asked at least once a year about the occurrence of falls ${ }^{13}$. The conditions that can lead to falls should be identified, pre- vented, and treated, including the inappropriate use of drugs, orthostatic hypotension, dementia, depression, and changes in balance and muscle strength, which, combined with the increased prevalence of osteoporosis, can significantly increase the risk of fractures in this group ${ }^{30}$. There is evidence that prevention programs conducted in communities and in long-term institutions are effective for decreasing the incidence of falls. Therefore, professionals need training to assist the elderly population the in areas of geriatrics and gerontology ${ }^{13}$.

It is important to note that elderly people should not be excessively worried about the risk of falls and their complications because this attitude can further aggravate the feeling of low self-efficacy or low confidence in avoiding falls. They should acknowledge that these falls are not intentional but are due to health problems that should be investigated and treated properly. Therefore, falls should be treated as a health problem and not as an option that is under the control of the patient.

This study addressed important aspects related to falls and traffic accidents involving elderly people but has some limitations. First, it could not use the sample weights in applying the twostep cluster procedure. However, even among statisticians, the use of weights in the estimates is a controversial issue, and not having used weights does not invalidate the results obtained ${ }^{31}$. Despite these limitations, the study paves the way for the development of targeted interventions based on the clusters we created, which have indicated specific types of individuals who can be more directly assisted by health care services. 


\section{Collaborations}

MG Freitas, PF Bonolo, and CJ Machado worked on the study design, the preparation of the initial and final versions of the manuscript, and on the final draft; MG Freitas and CJ Machado worked on the methodology; EN de Moraes worked on the initial and final versions of the manuscript; all authors worked on the critical revision of the manuscript and read and approved the final version.

\section{References}

1. Instituto Brasileiro de Geografia e Estatística (IBGE). Censo demográfico 2010. Sinopse do censo e resultados preliminares do universo. Rio de Janeiro: IBGE; 2011. [acessado em 2014 jun 30]. Disponível em: http:// www.ibge.gov.br/home/presidencia/noticias/imprensa /ppts/0000000402.pdf

2. Assis M. Envelhecimento ativo e promoção da saúde: reflexão para as ações educativas com idosos. Rev APS 2005; 8(1):15-24.

3. Veras R. Envelhecimento populacional contemporâneo: demandas, desafios e inovações. Rev Saude Publica 2009; 43(3):548-554.

4. Minayo MCS. O envelhecimento da população brasileira e os desafios para o setor saúde. Cad Saude Publica 2012; 28(2):208-209.

5. Ayres JRCM, Calazans GJ, Saletti-Filho HC, França-Júnior I. Risco, vulnerabilidade e práticas de prevenção e promoção da saúde. In: Campos GWS, Bonfim JRA, Minayo MCS, Akerman M, Júnior MD, Carvalho YM, organizadores. Tratado de Saúde Coletiva. São Paulo: Hucitec; 2014. p. 117-139.

6. Silva A, Faleiros HH, Shimizu WAL, Nogueira LM, Nhãn LL, Silva BMF, Otuyama PM. Prevalência de quedas e de fatores associados em idosos segundo etnia. Cien Saude Colet 2012; 17(8):2181-2190.

7. Minayo MCS. Violência contra idosos: relevância para um velho problema. Cad Saude Publica 2003; 19(3):783-791.

8. Terroso M, Rosa N, Marques AT, Simões R. Physical consequences of falls in the elderly: a literature review from 1995 to 2010. Eur Rev Agin Phys Act 2014; 11:5159.

9. Yiannakoulias N, Rowe BH, Svenson LW, Schopflocher DP, Kelly K, Voaklander DC. Zones of prevention: the geography of fall injuries in the elderly. Soc Sci Med 2003; 57(11):2065-2073.

10. Reichenheim ME, Souza ER, Moraes CL, Jorge MHPM, Silva CMFP, Minayo MCS. Violência e lesões no Brasil: efeitos, avanços alcançados e desafios futuros. [site da Internet]. [acessado 2014 jun 30]. Disponível em: http://download.thelancet.com/flatcontentassets/pdfs/ brazil/brazilpor5.pdf.

11. Phillips J, Walford N, Hockey A, Foreman N, Lewis M. Older people and outdoor environments: pedestrian anxieties and barriers in the use of familiar and unfamiliar spaces. Geoforum 2013; 47:113-124.

12. Gawryszewski VP. A importância das quedas no mesmo nível entre idosos no estado de São Paulo. Rev Assoc Med Bras 2010; 56(2):162-167.

13. Maciel A. Quedas em idosos: um problema de saúde pública desconhecido pela comunidade e negligenciado por muitos profissionais da saúde e por autoridades sanitárias brasileiras. Rev Med Minas Gerais 2010; 20(4):554-557.

14. Neves ACM, Mascarenhas MDM, Silva MMA, Malta DC. Perfil das vítimas de violências e acidentes atendidas em serviços de urgência e emergência do Sistema Único de Saúde em Capitais Brasileiras - 2011. Epidemiol Serv Saúde 2013; 22(4):587-596.

15. Verma JP. Cluster Analysis: For Segmenting the Population. 2013 In: Verma JP, editor. Data Analysis Management with SPSS software. New Delhi: Springer India; 2013. p. 317-358. 
16. Shih MY, Jheng JW, Lai LF. Two-Step Method for Clustering Mixed Categorical and Numeric Data. Tamkang Journal of Science and Engineering 2010; 13(1):11-19.

17. IBM Spss Statistics Base. [acessado 2014 jul 10]. Disponível em: http://www.spss.com.br/software/statistics/ download/IBM\%20SPSS\%20Statistics\%20Base $\% 20$ Especificacoes\%2021.pdf

18. Cluster Analysis. [acessado 2014 nov 26]. Disponível em: http://www.norusis.com/pdf/SPC_v13.pdf

19. Tinetti ME. Preventing Falls in Elderly Persons. N Engl J Med 2003; 348(1):42-49.

20. Shim EY, Ma SH, Hong SH, Lee YS, Paik WY, Seo DS, Yoo EY, Kim MY, Yoon JL. Correlation between frailty level and adverse health-related outcomes of community-dwelling elderly, one year retrospective study. Korean J Fam Med 2011; 32(4):249-256.

21. Tinetti ME, Inouye SK, Gill TM, Doucette JT. Shared risk factors for falls, incontinence, and functional dependence: unifying the approach to geriatric syndromes. JAMA 1995; 273(17):1348-1353.

22. Tinetti ME, Williams CS. Falls, Injuries Due to Falls, and the Risk of Admission to a Nursing Home. N Engl J Med 1997; 337(18):1279-1284.

23. Soriano TA, DeCherrie LV, Thomas DC. Falls in the community-dwelling older adult: a review for primarycare providers. Clin Interv Aging 2007; 2(4):545-554.

24. Maia BC, Viana OS, Arantes PMM, Alencar MA. Consequências das quedas em idosos vivendo na comunidade: revisão sistemática. Rev. Bras. Geriatr. Gerontol 2011; 14(2):381-394.

25. Boyd CM, Xue QL, Guralnik JM, Fried LP. Hospitalization and development of dependence in activities of daily living in a cohort of disabled older women: the Women's Health and Aging Study I. J Gerontol A Biol Sci Med Sci 2005; 60(7):888-893.

26. Piovesan AC, Pivetta HMF, Peixoto JMB. Fatores que predispõem a queda em idosos residentes na região oeste de Santa Maria, RS. Rev. Bras. Geriatr. Gerontol; 14(1):75-84.

27. Parreira JG, Vianna AMF, Cardoso GS, Karakhanian, WZ, Calil D, Perlingeiro JAG, Soldá SC, Assef JC. Lesões graves em vítimas de queda da própria altura. Rev Assoc Med Bras 2010; 56(6):660-664.

28. Vinic ALT, Bahia CA, Malta DC, Mascarenhas MDM, Montenegro MMS, Silva MMA, Monteiro RA. Perfil e tendência dos acidentes de transporte terrestre no Brasil, 2000 a 2012. In: Brasil. Ministério da Saúde (MS). Secretaria de Vigilância em Saúde. Saúde Brasil 2013: uma análise da situação de saúde e das doenças transmissiveis relacionadas à pobreza. Brasília: MS; 2014. p. 177-194.

29. Júnior $C A B$, Folchini AB, Ruediger RR. Estudo comparativo entre o trauma em idosos e não idosos atendidos em um Hospital Universitário de Curitiba. Rev. Col. Bras. Cir. 2013; 40(4):281-286.

30. Ganz DA, Bao Y, Shekelle PG, Rubenstein LZ. Will my patient fall? JAMA 2007; 297(1):77-86.

31. Ciol MA, Hoffman JM, Dudgeon BJ, Shumway-Cook A, Yorkston KM, Chan L. Understanding the use of weights in the analysis of data from multistage surveys. Arch Phys Med Rehabil 2006; 87(2):299-303.

Article Submitted on 09/24/2014

Approved on 12/01/2014

Final version submitted on 12/03/2014 